\title{
Mineralogy of the mafic anomaly in the South Pole-Aitken Basin: Implications for excavation of the lunar mantle
}

\author{
C. M. Pieters, S. Tompkins ${ }^{1}$, J. W. Head, P. C. Hess \\ Department of Geological Sciences Brown University, Providence, RI 02912
}

\begin{abstract}
The mineralogy of South Pole-Aitken Basin [SPA] (the largest confirmed impact basin on the Moon) is evaluated using five-color images from Clementine. Although olivinerich material as well as basalts rich in clinopyroxene are readily identified elsewhere on the farside, the dominant rock type observed across the interior of SPA is of a very noritic composition. This mineralogy suggests that lower crust rather than the mantle is the dominant source of the mafic component at SPA. The lack of variation in observed noritic composition is probably due to basin formation processes, during which extensive melting and mixing of target materials are likely to occur.
\end{abstract}

\section{Introduction}

The detection of a low-albedo mafic anomaly associated with the South Pole-Aitken (SPA) Basin by Galileo instruments [Belton et al., 1991] focused interest on the poorlyexplored lunar farside and renewed questions about the formation and evolution of the lunar crust and mantle. The existence of this ancient huge basin had been recognized since the late 1960's (see references in Head et al., [1993]) and its major boundaries were mapped [Stuart-Alexander, 1978; Wilhelms, 1987]. The Clementine laser altimeter characterized the full dimensions of SPA and showed it to be $2500 \mathrm{~km}$ in diameter and more than $8 \mathrm{~km}$ deep [Spudis et al., 1994; Zuber et al., 1994]. As the largest confirmed basin on the Moon (and perhaps the largest in the Solar System) SPA may indeed have excavated through the crust and into the mantle.

The mineralogy of the lunar crust and upper mantle has been estimated by several authors; for comparison we have used the Clementine 5-color multispectral UVVIS camera [Nozette et al., 1994] to perform a first-order evaluation of SPA mineralogy.

In order to assess the mineralogy of SPA, we selected a representative traverse of Clementine UVVIS data radial to the basin at $182^{\circ}$ longitude (MI shown in Figure 1) extending from the exterior $\left(10^{\circ} \mathrm{S}\right)$ to the center $\left(60^{\circ} \mathrm{S}\right)$. Calibration procedures and data properties are described in Pieters et al. [1996a] and McEwen and Robinson [1997]. Supplemental data also included in this analysis are twelve central peaks of large craters [Tompkins and Pieters, 1997], and two shorter mosaics (M2 $=157^{\circ}$ long., $20-40^{\circ} \mathrm{S} ; \mathrm{M} 3=225^{\circ}$ long., $60-70^{\circ} \mathrm{S}$ ).

'Now at Science Applications International Corporation, Chantilly, VA 20151

Copyright 1997 by the American Geophysical Union.

Paper number $97 \mathrm{GL} 01718$

0094-8534/97/97GL-01718\$05.00

\section{Source of SPA Mafic Component}

Several possible sources or causes for the observed extensive mafic anomaly at SPA have been proposed [Head et al., 1993; Pieters et al., 1993; Lucey et al., 1996], each with distinct mineralogical implications (or predictions). The mineralogy of materials at SPA should constrain which of the following are most plausible.

ExCAvated Mantle. Equilibrium and fractional crystallization models for the lunar mantle [Snyder et al., 1992; Taylor, 1982] describe clinopyroxene, olivine, and pigeonite as the mafic minerals present in the upper part of the mantle. Such compositions are consistent with many of the multiple saturation experiments (summarized in Longhi, [1992]). Alternatively, according to the density instability ("overturn") model [e.g., Hess and Parmentier, 1995], the post-overturn mantle immediately below the lunar crust is composed of mafic dunite cumulates from the magma ocean with $\mathrm{Mg}^{*}$ values $>90$ and/or samples of the primitive lunar interior which have undergone extensive pressure-release melting [Hess, 1994]. Such a mantle residue may be harzburgitic in character.

EXPOSEd Lower CRUST. There are geochemical arguments that the lower crust is more mafic than the anorthositic upper crust, and noritic in particular, i.e. containing low-Ca pyroxene [Ryder and Wood, 1977; Spudis and Davis, 1986]. Plutons, the preferred source for the $\mathrm{Mg}$-rich suite of highland rocks [Warren, 1985], are thought to concentrate in the lower crust.

Melt Sheet. Large impact events are expected to produce proportionally larger volumes of impact melt [Melosh, $1989 \mathrm{p}$. 123; Cintala and Grieve, 1994], and the process would mix and perhaps homogenize the total melt. The melt sheet should thus, to a first order, represent the bulk composition of the stratigraphic column involved in the melting event. If the

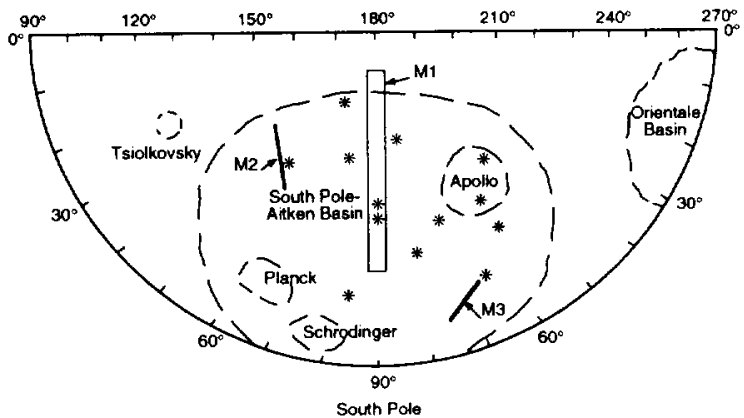

Figure 1. Sketch map of SPA (after Wilhelms [1987]) showing principal geologic features and location of Clementine multi spectral data analyzed. Asterisks indicate central peaks of large craters included in Tompkins and Pieters [1997]. The central mosaic is shown in Figure 2. 
melt sheet itself is sufficiently large and thoroughly melted, it may differentiate [Grieve et al., 1991].

CrYPTOMARE. Since SPA is an ancient pre-Nectarian basin, it is plausible that early volcanism filled much of the basin interior and was subsequently partially masked by debris from later basin-forming events [Head and Wilson, 1992; Head et al., 1993]. Such cryptomaria should exhibit a basaltic character, i.e., high-Ca pyroxene as the dominant mafic mineral.

\section{Rock and Soil Types Within SPA}

An image of the $750 \mathrm{~nm}$ mosaic of Clementine data through SPA is shown in Fig. 2. The mosaic traverses about $1500 \mathrm{~km}$ from $10^{\circ} \mathrm{S}$ to $60^{\circ} \mathrm{S}$ and is $43 \mathrm{~km}$ wide at the northern part of the strip. The relative brightness of features are illustrated in this photometrically corrected mosaic. The locations of areas for which representative spectra have been extracted for this discussion are shown with small arrows.

Reflectance spectra for minerals of the principal rock types on the Moon contain diagnostic absorptions in the near-

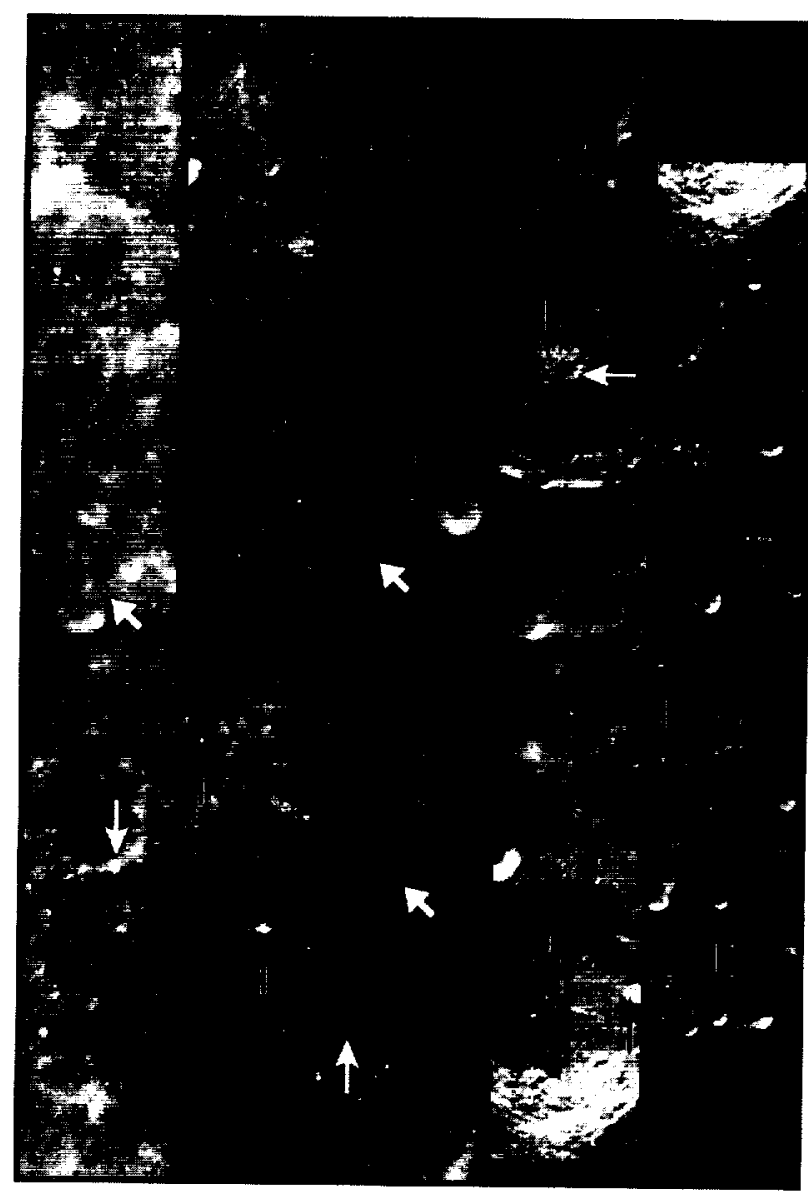

Figure 2. Mosaic of $750 \mathrm{~nm}$ data for 67 frame sets through SPA at $182^{\circ}$ longitude. $10^{\circ} \mathrm{S}$ is upper left and $60^{\circ} \mathrm{S}$ is lower right. A portion of the previous mosaic section is repeated at the top of each subsection. The outer ring of SPA defined by Stuart-Alexander [1978] is shown in solid heavy lines. Finsen (top) and Alder (bottom) are the two large craters in the 4th subsection. Spectra locations ( $3 \times 3$ pixels) are shown for Fig. 3 (white arrows) and for Fig. 4 (black arrows). White diagonal arrows are for soil areas; all others are for craters or crater features.

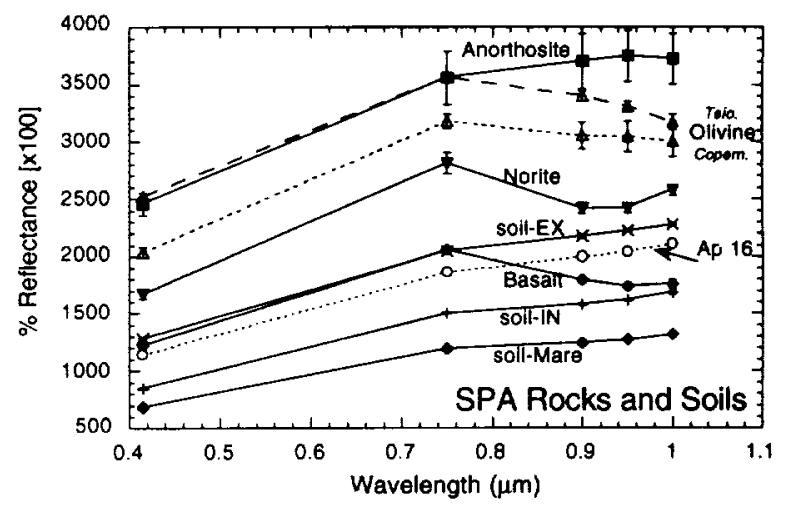

Figure 3. Representative 5-color spectra for rock and soil types found in the SPA region (solid lines; white arrows in Fig. 2). Low-Ca pyroxene indicating a noritic composition is readily recognized by the relatively short wavelength $\mathrm{Fe}^{2+}$ absorption. Similarly, high-Ca pyroxenes with a longer wavelength ferrous absorption are evident in the basalt ponds. (Apollo 16 highland soil and olivine-rich lithologies from Tsiolkovsky and Copernicus are shown for comparison.)

infrared [Adams, 1974; Pieters, 1993]. The most diagnostic absorption bands are due to $\mathrm{Fe}^{2+}$ in the mafic minerals and occur near 1 and $2 \mu \mathrm{m}$ for pyroxenes and just beyond $1 \mu \mathrm{m}$ for olivine. [Burns, 1993; Adams, 1974]. Plagioclase with minor amounts of iron $(0.1-0.5 \% \mathrm{FeO})$ is bright and exhibits no absorption near $1 \mu \mathrm{m}$, but has a broad feature near $1.25 \mu \mathrm{m}$.

A summary of Clementine 5-color spectra of the rock and soil types observed in association with SPA is shown in Fig. 3. The three principal rock types found are anorthosites (largely exterior to the basin; identified by their lack of ferrous absorption), anorthositic norites (pervasive throughout the basin; identified by a low-Ca pyroxene absorption near 0.93-0.95 $\mu \mathrm{m}$ ), and basalt (associated with the small mare ponds [Yingst and Head, 1997]; identified by their high-Ca pyroxene absorption at longer wavelengths near 0.98$1.00 \mu \mathrm{m}$ ). Candidate mantle materials (olivine-rich rock types) are shown for comparison but are not seen in these SPA data. Freshly exposed mafic rocks and breccias typically exhibit prominent absorption bands, but soils derived from these rock types are darker and have weaker absorptions due to space weathering.

With this limited spectral range, anorthosite, norite, mare basalt, and troctolite can be identified as primary rock types, but other mineral mixtures may be difficult to distinguish. For example, in mixtures of low- and high-Ca pyroxenes, the $\mathrm{Fe}^{2+}$ band center shifts systematically between 0.93 and $0.98 \mu \mathrm{m}$, depending on the relative abundance of low- and high-Ca pyroxene. Although the $\mathrm{Fe}^{2+}$ absorption of olivine is quite distinctive and olivine dominates a simple mixture with plagioclase (troctolite), olivine is normally less absorbing than pyroxene and is difficult to detect in a pyroxene mixture. The band center of mixtures of olivine and pyroxene is thought to be dominated by the pyroxene component until about $50 \%$ olivine is present [Cloutis and Gaffey, 1986].

SoILs. Highland soils exterior to the basin in the north are observed to be somewhat brighter than those of Apollo 16. This, coupled with the detection of abundant anorthosite, is indicative of the felsic (high $\mathrm{Al}$, low $\mathrm{Fe}$ ) composition of the topographically high terrain [Zuber et al., 1994] north of SPA basin. The soils interior to SPA are darker and have a slightly 


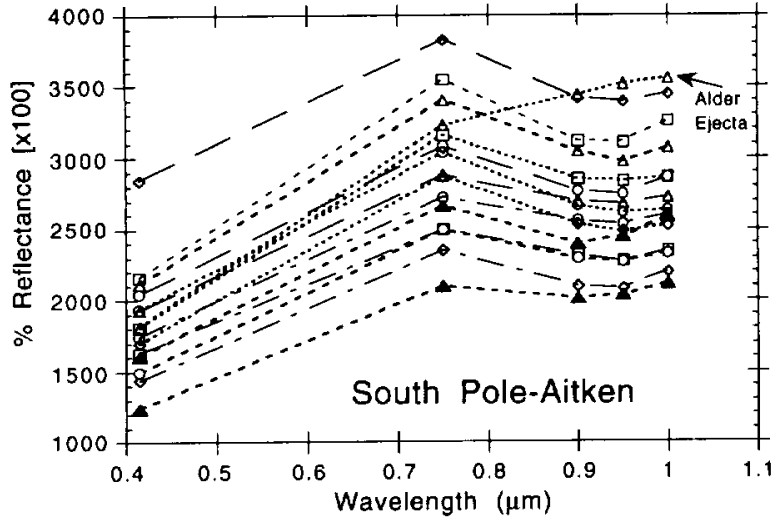

Figure 4. Five-color spectra of fresh craters (black arrows in Fig. 2) of all sizes within South Pole-Aitken, including central peaks (solid triangles). These spectra indicate low-Ca pyroxene is the dominant mafic mineral throughout SPA. Spectra from each subsection in Fig. 2 are shown with different line types (with decreasing dash lengths toward the south).

stronger ferrous absorption, leading to the identification of SPA as mafic, or Fe-rich [Belton et al., 1992; Head et al., 1993; Pieters et al., 1993; Lucey et al., 1995]. Soils developed on mare ponds within SPA are the darkest and often have somewhat stronger ferrous absorptions.

CRATERS. Freshly exposed SPA material at both small and large craters, which sample from 0.2 to $10 \mathrm{~km}$ depth, exhibit relatively short wavelength ferrous absorptions, characteristic of the same general composition: anorthositic norite to noritic anorthosite. Five-color spectra for such areas, shown in Fig. 4, are remarkably similar and indicate low-Ca pyroxene is the dominant mafic mineral present across SPA basin. This pyroxene is also relatively abundant, and this same noritic composition is seen in all the parts of SPA studied. Although several areas may consist of rock types that contain a mixture of two pyroxenes, no areas have been observed that are gabbroic in character (with high-Ca being the dominant mafic mineral). Similarly, no olivine-plagioclase lithologies are observed in these SPA data, unlike the troctolite seen in central peaks of craters such as Copernicus and Tsiolkovsky [e.g. Pieters 1993; Pieters et al., 1996b]. Data with this limited spectral range, however, can be ambiguous and cannot rule out the possible presence of olivine mixed with pyroxene up to 1:1. Precise high spectral resolution data to $2.5 \mu \mathrm{m}$ are required to detect abundant olivine in olivine/pyroxene mixtures.

Although the possible presence of olivine in southern SPA was suggested by 6-color Galileo data [Pieters et al., 1993], such an interpretation was somewhat weakened by data recalibration with a scattered light model [Gaddis et al., 1995]. No olivine-rich species are detected across the area with 5-color Clementine data (M3 in Fig. 1).

The pervasive noritic composition observed throughout SPA, of course, does not necessarily mean all the norites are geochemically equivalent. We have not attempted to quantify opx/plag ratio nor $\mathrm{Mg}^{*}$ with this limited spectral information.

There are only a few exceptions to the dominance of norite in SPA. Anorthosite is seen in a few rare cases within the basin: 1) in a NW ring of Ingenii basin, not far from the estimated edge of SPA and 2) in a localized occurrence in the south wall and ejecta of the $75 \mathrm{~km}$ crater Alder located within the SPA basin (see Figure 2). The east wall and some of Alder's central peaks exhibit the diagnostic features of a noritic composition, but one central peak and most of the entire south wall is anorthosite and almost devoid of mafic minerals.

\section{Interpretations and Implications}

The prominent transition from a very anorthositic composition just exterior to SPA to a very pyroxene-rich (noritic) rock type on the interior of SPA suggests the original upper crust at SPA has been stripped away. The lack of evidence for significant olivine or high-Ca pyroxene lithologies detected within the basin suggests no mantle outcrops have been directly observed within this representative sampling of SPA. This suggests little, if any, mantle has been excavated, although small amounts are not precluded [Melosh, 1989; Spudis 1993].

Although SPA is indeed mafic-rich, the lack of high-Ca pyroxene also indicates basaltic cryptomaria cannot be a significant contributor to the mafic character observed in this traverse across the basin. No localized cryptomaria have yet been detected in SPA, even though the small mare ponds emplaced later are basaltic in composition.

The uniformity of the noritic presence observed throughout SPA has several important implications. Since the same rock type is seen in craters a few $\mathrm{km}$ in diameter as well as craters as large as Finsen $(\sim 85 \mathrm{~km})$, there appears to be little significant vertical or horizontal compositional variation across this huge basin. We believe the most reasonable interpretations of the pervasive SPA noritic rock type are: 1) a very homogeneous noritic lower lunar crust, 2) an extensive homogenized melt sheet, or 3) some combination of the two.

If the interior of SPA is a huge melt sheet, then it has not differentiated into compositional layers with distinct mineralogy. Instead, the relatively homogeneous mineralogy represents the bulk properties of the melted target material. We interpret this to be predominantly lower crust. Equally consistent with the data, however, would be a very homogeneous noritic lower crust, brecciated and exposed by the SPA impact event. The third option, a well mixed melt sheet overlying remnant lower crust of the same composition, may be the most realistic and accounts for the vertical and lateral scale of the homogeneity.

In conclusion, we interpret the mineralogical evidence from these Clementine data to indicate that the SPA impact event created deposits in its interior that are composed predominantly of lower crustal material, despite the extremely large size of the basin. This interpretation (summarized in Fig. 5) relies on studies which show that impact melt remaining in the basin interior will be derived largely from some of the deeper layers encountered in the excavation processes [Melosh, 1989; Grieve et al., 1991; Cintala and Grieve, 1994], e.g., the lower crust in our interpretation of SPA. It is possible that some of the exposed deposits may contain local concentrations of excavated mantle due to the geometry of the excavation cavity such that a diminishing sma!ler portion of the material excavated is derived from the lower excavated depths [Head et al., 1975; Spudis, 1993].

No firm mineralogical evidence of mantle material has yet been seen at this scale. Many current models of basin excavation predict that impact melt of SPA should be nearly pure mantle (e.g., discussed in Lucey et al., [1996]) but our results suggest that these models may need revision, or that other factors, such as oblique impact [Schultz, 1997] may account for these observations. Our lower crust interpretation of SPA is 


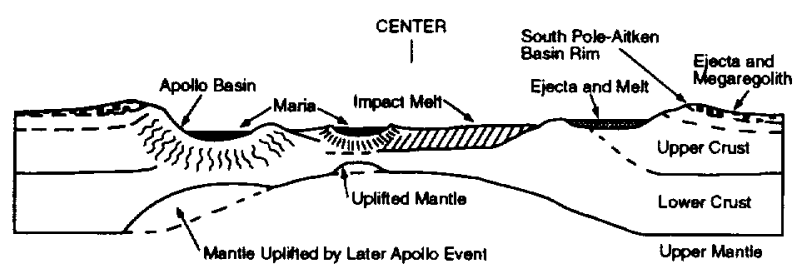

Figure 5. Schematic cross section across SPA illustrating the relations of surface and subsurface crustal components (modified from Head et al., [1993]). The interior of SPA is dominated by noritic lithologies from the lower crust.

consistent with estimates of the present thickness of crust remaining at SPA, which has been modeled to be $\sim 30-40 \mathrm{~km}$ using a simple low density crustal model [Zuber et al., 1994; Neumann et al., 19961, and with the fact that even for post-SPA impacts in the basin interior, no evidence of mantle mineralogy has yet been observed [Tompkins and Pieters, 1997].

Acknowledgments: Support from NASA grants NAGW-28 and NAGW-5101 (CMP), NAGW-1873 (JWH), and NAGW-3613 (PCH) is gratefully acknowledged. Assistance by George $\mathrm{He}$ in producing Clementine data products is much appreciated.

\section{References}

Adams, J. B., Visible and near-infrared diffuse reflectance spectra of pyroxenes as applied to remote sensing of solid objects in the solar system, J. Geophys. Res. 79, 4829-4836, 1974.

Belton, M.J.S., J.W. Head, C.M. Pieters, R. Greeley, A.S. McEwen, G. Neukum, K.P. Klaasen, et al., Lunar impact basins and crustal heterogeneity: New western limb and far side data from Galileo, Science, 255, 570-576, 1992.

Burns, R. G., Mineralogical Application of Crystal Field Theory, Second Ed., Cambridge Univ. Press, Cambridge, 551 pp., 1993.

Cintala, M. J. and R. A. F. Grieve, The effects of differential scaling of impact melt and crater dimensions on lunar and terrestrial craters: Some brief examples, in Large meteorite Impacts and Planetary Evolution, edited by B. O. Dressler, R. A. F. Grieve and V. L. Sharpton, Geol. Soc. Amer. Spec. Pap. 293, Boulder, 1994

Cloutis, E.A., M. J. Gaffey, T. L. Jackowski, and K. L. Reed, Calibrations of Phase Abundance, Composition, and Particle Size Distribution for Olivine-Orthopyroxene Mixtures from Reflectance Spectra, $J$. Geophys. Res., 91, B11, 11641-11653, 1986.

Gaddis, L., A. McEwen, and T. Becker, Compositional variations on the Moon: Recalibration of Galileo solid-state imaging data for the Orientale region and farside, $J$. Geophys. Res., 100, E12, 26345-26355, 1995.

Grieve, R.A.F., D. Stoffler, and A. Deutsch, The Sudbury structure: Controversial or misunderstood?, J. Geophys. Res. 96, 22753-22764, 1991.

Head, J. W. and L. Wilson, Lunar mare volcanism: Stratigraphy, eruption conditions, and the evolution of secondary crusts, Geochim. Cosmachim. Acta, 56, 2155-2175, 1992

Head, J. W., M. Settle and R. S. Stein, Volume of material ejected from major basins and implications for the depth of excavation of lunar samples, Proc. Lunar Sci. Conf. 6, 2805-2829, 1975.

Head, J.W., S. Murchie, J.F. Mustard, C.M. Pieters, G. Neukum, A. McEwen, R. Greeley, and M.J.S. Belton, Lunar impact basins: New data for the western limb and farside (Orientale and South PoleAitkin Basins) from the first Galileo flyby, $J$. Geophys. Res., 98, No. E9, 17,149-17,181, 1993.

Hess, P.C., Petrogenesis of lunar troctolites. J. Geophys. Res. 99, 19,083$19,093,1994$.

Hess, P. C. and E. M. Parmentier, A model for the thermal and chemical evolution of the Moon's interior: Implications for the onset of mare volcanism, Earth and Planet. Sci. Let., 134, 501-514, 1995.

Longhi, J., Experimental petrology and petrogenesis of mare volcanics, Geochim. Cosmochim. Acta 56, 2235-2251, 1992.

Lucey, P. G., G. J. Taylor, and E. Malaret, Abundance and distribution of iron on the Moon, Science 268, 1150-1153, 1995.

Lucey, P. G., G. J. Taylor, B. R. Hawke, and P. D. Spudis, Iron and titanium concentration in South Pole-Aitken Basin: Implications for Lunar mantle composition and basin formation, Lunar Planet. Sci. XXVII (abstract), 783-784, 1996.

McEwen, A. S. and M. S. Robinson, Mapping of the Moon by Clementine, Advances in Space Research, in press, 1997.

Melosh, H. J., Impact Cratering: A Geologic Process, 254 pp., Oxford University Press, New York, 1989.

Neumann G. A., M. T. Zuber, D. E. Smith, and F. G. Lemoine, The lunar crust: Global structure and signature of major basins, $J$. Geophys. Res., 101, 16841-16863, 1996.

Nozette S., P. Rustan, L.P. Pleasance, D.M. Horan, P. Regeon, E.M. Shoemaker, P.D. Spudis, et al., The Clementine Mission to the Moon: Scientific Overview, Science, 266, 1835-1839, 1994.

Pieters, C.M., Compositional diversity and stratigraphy of the Lunar crust derived from reflectance spectroscopy, in Remote Geochemical Analysis: Elemental and Mineralogical Composition., edited by C.M. Pieters and P.A.J. Englert, 309-339, Cambridge Univ. Press, New York, 1993.

Pieters, C.M., J.W. Head, J.M. Sunshine, E.M. Fischer, S.L. Murchie, M. Belton, A. McEwen, L. Gaddis, R. Greeley, G. Neukum, R. Jaumann, and $\mathrm{H}$. Hoffmann, Crustal diversity of the Moon: Compositional analyses of Galileo SSI data, J. Geophys. Res., 98, No. E9, 17,12717,148, 1993.

Pieters, C.M., G. He, M. Staid, S. Tompkins, and E. Fischer, internet web site: http://www.planetary.brown.edu/clementine/calibration html, 1996a.

Pieters, C.M., G. He and S. Tompkins, Anorthosite and Olivine Layers of the Farside Upper Crust at Tsiolkovsky, Lunar and Planetary Science XXVII (abs.), LPI, Houston, TX, 1035-1036, 1996b.

Ryder, G. and J.A. Wood, Serenitatis and Imbrium impact melts: Implications for large-scale layering in the lunar crust, Proc. Lunar Sci. Conf. 8th, 655-668, 1977.

Schultz, P. H., Forming the South Pole-Aitken Basin: The extreme games, Lunar and Planetary Science XXVIII (abs.), 1259-1260, 1997.

Snyder, G.A., L.A. Taylor, and C. Neal, A chemical model for generating the sources of mare basalts: Combined equilibrium and fractional crystallization of the lunar magmasphere, Geochim. Cosmochim. Acta, 56, 3809-3823, 1992.

Spudis, P. D., The Geology of Multi-Ring Impact Basins, 263 pp., Cambridge University Press, New York, 1993.

Spudis, P.D. and P.A. Davis, A chemical petrological model of the lunar crust and implications for lunar crustal origin, J. Geophys. Res., 9I, (B13), E84-E90, 1986

Spudis, P.D., R. A. Reisse, and J. J. Gillis, Ancient multiring basins on the Moon revealed by Clementine laser altimetry, Science, 266, 1848$1851,1994$.

Stuart-Alexander, D., Geologic map of the central far side of the Moon, USGS Map I-1047, 1978.

Taylor, S.R., Planetary Science: A Lunar Perspective, 481 pp., Lunar and Planetary Institute, Houston, 1982.

Tompkins, S. and C.M. Pieters, Composition of the Lunar crust beneath the megaregolith, Lunar Planet. Sci. XXVIII (abstract), 1997.

Warren, P.H., The magma ocean concept and lunar evolution, Ann. Revs. Earth Planet. Sci. 13201-13240, 1985.

Wilhelms, D., The Geologic History of the Moon, U.S. Geol. Surv. Prof Pap. 1348, 302 pp., 1987.

Yingst, A. and J.W. Head, Multispectral analysis of mare deposits in South Pole/Aitken Basin, Lunar Planet. Sci. XXVIII (abstract), 1997.

Zuber, M.T., D.E. Smith, F. Lemoine, and G.A. Neumann, The shape and internal structure of the Moon from the Clementine Mission, Science, 266, 1839-1843, 1994.

(Received February 21, 1997; accepted April 28, 1997) 